\title{
Article
}

\section{A Pharmacology-Based Enrichment Program for Undergraduates Promotes Interest in Science}

\author{
Elizabeth A. Godin, ${ }^{*}$ Stephanie V. Wormington, ${ }^{\dagger}$ Tony Perez, ${ }^{\ddagger}$ Michael M. Barger, $\$$ \\ Kate E. Snyder," Laura Smart Richman, ${ }^{\S}$ Rochelle Schwartz-Bloom,* \\ and Lisa Linnenbrink-Garcia ${ }^{\dagger}$
}

*Pharmacology \& Cancer Biology, Duke University Medical Center, Durham, NC 27710; ${ }^{\dagger}$ Department of Counseling, Educational Psychology, \& Special Education, Michigan State University, East Lansing, MI 48824; 抽 Psychology \& Neuroscience, Duke University, Durham, NC 27708; "Educational Psychology, Measurement \& Evaluation, University of Louisville, Louisville, KY 40292

Submitted February 28, 2015; Revised August 8, 2015; Accepted August 8, 2015

Monitoring Editor: Erin Dolan

\begin{abstract}
There is a strong need to increase the number of undergraduate students who pursue careers in science to provide the "fuel" that will power a science and technology-driven U.S. economy. Prior research suggests that both evidence-based teaching methods and early undergraduate research experiences may help to increase retention rates in the sciences. In this study, we examined the effect of a program that included 1) a Summer enrichment 2-wk minicourse and 2) an authentic Fall research course, both of which were designed specifically to support students' science motivation. Undergraduates who participated in the pharmacology-based enrichment program significantly improved their knowledge of basic biology and chemistry concepts; reported high levels of science motivation; and were likely to major in a biological, chemical, or biomedical field. Additionally, program participants who decided to major in biology or chemistry were significantly more likely to choose a pharmacology concentration than those majoring in biology or chemistry who did not participate in the enrichment program. Thus, by supporting students' science motivation, we can increase the number of students who are interested in science and science careers.
\end{abstract}

\section{INTRODUCTION}

Many students enter college with an interest in studying science and may even contemplate careers in biomedical and behavioral sciences. However, after enrolling in introductory-level science courses, students often decide to pursue non science majors. Fewer than $40 \%$ of students who enter

CBE Life Sci Educ December 1, 2015 14:ar40

DOI:10.1187/cbe.15-02-0043

Address correspondence to: Elizabeth A. Godin (elizabeth.godin @duke.edu).

(c) 2015 E. A. Godin et al. CBE-Life Sciences Education (c) 2015 The American Society for Cell Biology. This article is distributed by The American Society for Cell Biology under license from the author(s). It is available to the public under an Attribution-Noncommercial-Share Alike 3.0 Unported Creative Commons License (http:/ / creativecommons.org/licenses/by-nc-sa/3.0).

"ASCB ${ }^{\circledR}$ "and "The American Society for Cell Biology ${ }^{\circledR}$ " are registered trademarks of The American Society for Cell Biology. college with an interest in science actually complete a degree in science, technology, engineering, or mathematics (STEM) fields (President's Council of Advisors on Science and Technology [PCAST], 2012; Chen, 2013). This issue has led to the term the "leaky pipeline." Research that addresses the leaky pipeline indicates that enriched curricular opportunities and early undergraduate research experiences are important factors in enhancing students' interest in science and students' confidence in their abilities to pursue a science career (Frantz et al., 2006; McGee and Keller, 2007; Russell et al., 2007; Harrison et al., 2011; Graham et al., 2013). Moreover, there have been a number of calls to use evidence-based teaching methods to improve retention in STEM fields (Handelsman et al., 2004) and to improve the quality of teaching at the college level (PCAST, 2012).

With these goals in mind, we created an undergraduate pharmacology enrichment program, building from research on best practices from educational and psychological theories of learning and motivation. We chose a pharmacology 
focus for the program, as pharmacology integrates biology and chemistry-two gateway subjects in biomedical science for undergraduates. Moreover, topics in pharmacology (e.g., how drugs work to cause or cure diseases) are especially useful for making real-world connections, one of our five motivational design principles detailed below. As we describe in the following sections, the program consisted of 1) a Summer enrichment 2-wk minicourse in pharmacology for rising sophomores at a private university in the southeastern United States and 2) a research course during the subsequent Fall semester in which students generated their own proposals and carried out empirical research.

The pharmacology enrichment program was developed based on current theories regarding students' learning and motivation. From a learning theory perspective, we sought to actively engage students in the learning process by following principles of constructivism, which emphasizes students' own construction of knowledge through active engagement with learning material (Palincsar, 1998; Hmelo-Silver et al., 2007). An emphasis on active learning is certainly not new (e.g., see Ebert-May et al., 1997; Dickman et al., 2002), but it is often absent from undergraduate education in STEM fields. Moreover, the benefits of employing active learning are supported by current research. Active learning has been linked to higher-level learning, including problem solving and a deeper understanding of course material (Haak et al., 2011; Jensen and Lawson, 2011), both of which are important for success in the sciences. A recent meta-analysis of 225 studies comparing active learning with traditional lecturing in undergraduate STEM courses indicated that the use of at least some active-learning instructional techniques was associated with an increase in student performance (assessment scores) and a decrease in failure rates (Freeman et al., 2014).

Equally important is the consideration of students' motivation. Indeed, motivation becomes critically important when students face challenging course work that requires high levels of engagement, a common occurrence in STEM fields. Drawing from current motivational research on instructional supports for students' perceived competence, interest, and value for a particular subject area or field of study (Turner et al., 2011; Linnenbrink-Garcia et al., 2013), we identified five key motivational design principles to incorporate into our enrichment program: 1) inclusion of real-world challenging tasks, 2) provision of choice surrounding academic tasks, 3) encouragement of active involvement, 4) support for feelings of belonging, and 5) use of effort-based evaluation.

Our evaluation of the pharmacology enrichment program focused on three primary research questions. The first research question asked whether participation in an abbreviated, introductory Summer minicourse in pharmacology enhanced students' knowledge of biology and chemistry principles. Second, we examined students' overall motivation at the end of the introductory Summer minicourse and during the Spring semester after the Fall research course, focusing both on individual motivation and perceptions of the enrichment program as being relevant to real life, supporting autonomy and choice, allowing for active involvement, supporting feelings of belonging, and supporting a focus on learning and growth. Third, we asked whether there were differences in the proportion of students (biology and chemistry majors only) who opted to concentrate in pharmacology, comparing participants in our enrichment program with other biology and chemistry majors at the same institution.

\section{METHOD}

\section{Participants}

Over 4 yr, all students who took first-year chemistry courses at the private university were invited to participate in a pharmacology-based enrichment program that took place in the Summer after the students' first year in college (the program was tuition-free; however, there was a housing cost to live on campus). The recruitment information highlighted the benefits of participating, including: 1) adding to their resumes that they participated in a National Institutes of Health (NIH)-funded enrichment program, 2) the ability to engage in small-group learning with postdoctoral fellows and graduate students, 3) preparation for future biology and chemistry courses, and 4) preparation for independent study in a biomedical research lab. The research team reviewed the applications and accepted nearly all students who applied to the program each Summer (100\% of applicants accepted for cohorts 1,3, and 4; 97\% of applicants accepted for cohort 2).

The program consisted of two parts: 1) a 2-wk Summer minicourse and 2) a research course in the subsequent Fall semester. Over the course of $4 \mathrm{yr}$, students ( $n=58,71,64$, and 31, respectively) participated in the minicourse. Approximately half of those students in each year were randomly assigned (balanced by demographics such as race and gender) to participate in the Fall research course ( $n=28,34$, and 25 students from the first three cohorts). Any student declining to participate in the Fall research course (approximately three to five students each year) was replaced by random assignment by a student with the same demographic profile as the student who declined to participate. Owing to funding limitations, students participating in the fourth year of the minicourse were not given an option to participate in the Fall research component. The demographics of students participating over the $4 \mathrm{yr}$ are shown in Table 1.

The instructional staff for the Summer minicourse and Fall research course included graduate students and postdoctoral fellows in the basic sciences from both the private university and a nearby highly rated research-intensive public university. When choosing the program staff, we selected individuals with content knowledge related to pharmacology (or allied disciplines), some prior teaching experience, and a clear interest in gaining additional teaching experience at the undergraduate level. Additionally, we selected staff with good social and communication skills (e.g., individuals who were enthusiastic, engaged easily in conversation, were able to maintain eye contact, and provided clear oral responses to interview questions). Depending on the number of students attending the program each Summer, eight to 12 instructors were hired each year. The ratio of instructors to students was 1:6 during most small-group work. Of the 36 staff hired over $4 \mathrm{yr}, 72 \%$ were female and 14\% were underrepresented minorities (URMs). The instructional staff provided the daily hour-long interactive lectures in pharmacology, implemented problem-based learning activities, and mentored students to develop hypothetical research projects during the minicourse. In the Fall, a portion of the Summer instructional staff were retained to provide individual 
Table 1. Demographics of participants in the pharmacology-based enrichment program ${ }^{\mathrm{a}}$

\begin{tabular}{lcc}
\hline & $\begin{array}{c}\text { Summer } \\
\text { minicourse } \\
(n=224)\end{array}$ & $\begin{array}{c}\text { Fall research } \\
\text { course }(n=87)\end{array}$ \\
\hline Gender & & \\
$\quad$ Male & $34.4 \%$ & $34.5 \%$ \\
$\quad$ Female & $65.6 \%$ & $65.5 \%$ \\
Race/ethnicity & & \\
$\quad$ African American or black & $15.6 \%$ & $16.1 \%$ \\
Asian, Pacific Islander, or Asian & $42.0 \%$ & $43.7 \%$ \\
$\quad$ American & & \\
$\quad$ European American, white (not & $25.4 \%$ & $21.8 \%$ \\
$\quad$ Hispanic), or Caucasian & $9.4 \%$ & $9.2 \%$ \\
$\quad$ Hispanic or Latino/a & $0.0 \%$ & $0.0 \%$ \\
$\quad$ Native American or American & & \\
$\quad$ Indian & $3.1 \%$ & $3.4 \%$ \\
$\quad$ Multiracial (not URM) & & \\
$\quad$ Multiracial (URM) & $4.5 \%$ & $5.7 \%$ \\
\hline
\end{tabular}

${ }^{a}$ Values represent percentage of program participant sample self-identifying as that category. URM indicates participants who identify as African American or black, Hispanic and Latino/a, or Native American or American Indian.

mentorship to small groups of four to six students engaging in independent research (see detailed description of each of the program components below). The instructional staff received up to a $\$ 4000$ stipend for participating in the program (those who participated in both the Summer and Fall components received the maximum stipend).

\section{Professional Development for the Instructional Staff}

The program directors (faculty members in pharmacology and psychology) delivered professional development to the instructional staff during two full-day workshops preceding the Summer minicourse and one full-day workshop preceding the Fall research course. During the first workshop, the faculty provided examples of how to deliver the lectures in an engaging manner (e.g., by including real-life situations) and how to serve as facilitators in small-group, problem-based learning activities. Best practices in teaching, including the five motivational design principles outlined above, were discussed (see the Supplemental Material for a sample presentation on motivation), and the faculty modeled several aspects of high-quality instruction, with the instructional staff serving as "students." In the second workshop, the faculty reviewed each of the inquiry-based activities and labs in detail. The instructional staff engaged in each of the lab activities together so they would be familiar with the execution, data collection, and statistical analyses. Finally, there was discussion about effective mentorship of small groups engaged in their own hypothetical (minicourse) or actual (Fall research course) research ideas and a review of the motivational design principles.

\section{Program Components}

The program consisted of two instructional components: an intensive Summer enrichment minicourse (no course credit) and a self-generated research course (with full course credit) the following Fall.

Summer Minicourse. The Summer minicourse took place on the campus of the private university for $2 \mathrm{wk}$ in May (Monday through Friday, $7 \mathrm{~h} / \mathrm{d}$ ). During the first week, students were introduced to fundamental concepts in pharmacology (see Table 2). In the second week, the drug treatment of four specific diseases was covered. Various learning techniques were used throughout the program, including 1) direct instruction; 2) problem-based and active learning; 3) small-group research and presentations; and 4) short, inquiry-based laboratory experiments. The general daily structure of the minicourse included a 1-h interactive lecture to introduce the concepts, followed by problem-based smallgroup learning (five to six students per instructor).

One key feature of the minicourse was the inclusion of four inquiry-guided lab activities, each of which focused on one of four drugs: aspirin, caffeine, tobacco, and alcohol. Specifically, the four activities involved the evaluation of 1) the extent to which aspirin partitions into aqueous versus organic solvents as a model of absorption, 2) the effect of caffeine in altering blood pressure and heart rate, 3) whether tobacco extracts can cause DNA mutations in bacteria, and 4) the degree of alcohol intoxication in Drosophila (fruit flies) that have two different polymorphisms of the alcohol dehydrogenase $(A D H)$ gene. Instead of being required to follow a list of prescribed procedures (i.e., the traditional cookbook-style laboratory), the students designed the lab experiments themselves under the guidance of the course instructors. We have included a sample lab (the alcohol intoxication in fruit flies) in the Supplemental Material. Necessary materials were provided, but the students generated the hypotheses and the experimental design based on their Web-based research and class discussion. During the labs, students also learned how to design and carry out the experiments as pharmacologists would (e.g., constructing a dose-response curve, scoring behavioral observations, being blind to the treatment). Finally, students learned basic information about data analysis and statistics that were appropriate for each experiment.

Another unique aspect of the minicourse included students' development of their own hypothetical research proposal during the 2-wk minicourse. On the first day, students were briefly introduced to the PubMed database and began formulating their ideas about the actions of a drug or toxin of interest to them. We supported student autonomy by giving them the opportunity to explore any topic in pharmacology. Over the $2 \mathrm{wk}$, students were given time to work individually on the introduction, hypothesis, and experimental design of their proposal, with the guidance of their instructors. On the final day of the minicourse, students participated in a poster session to present their hypothetical research to other instructors and their peers. The poster session was designed to mimic a proposal that one would prepare in graduate school; the session was also designed to prepare students for the Fall research course, during which they would generate and carry out their own real project (described below). Several examples of the hypothetical proposals are listed in Table 3 .

In addition to the development of the research proposal and the four inquiry-guided lab activities, there were a 
Table 2. Brief overview of syllabus for the Summer minicourse

\begin{tabular}{|c|c|}
\hline Overall topic & Specific activities $^{\mathrm{a}}$ \\
\hline \multicolumn{2}{|l|}{ Week 1: Fundamentals of drug action } \\
\hline \multirow{3}{*}{ Day 1: Drugs and drug targets } & Drug target activity \\
\hline & Research: introduction to PubMed \\
\hline & Introduction to concept mapping \\
\hline \multirow[t]{3}{*}{ Day 2: Drug absorption and distribution } & PBL: acids, bases, and cocaine addicts \\
\hline & Lab: aspirin lab \\
\hline & Neuroscience webinar \\
\hline \multirow[t]{3}{*}{ Day 3: Drug metabolism and excretion } & Pharmacokinetics activity \\
\hline & PBL: genes and steroids \\
\hline & Pen-pal letter writing \\
\hline \multirow[t]{2}{*}{ Day 4: Dose-response/drug toxicity } & Lab: dose-response of caffeine \\
\hline & Research: introduction and hypothesis \\
\hline \multirow[t]{3}{*}{ Day 5: Pharmacogenomics } & Lab: ADH flies and alcohol \\
\hline & Research: experimental procedures \\
\hline & Movie: Ms. Evers' Boys \\
\hline \multicolumn{2}{|l|}{ Week 2: Pharmacology and disease } \\
\hline \multirow[t]{2}{*}{ Day 6: Drug abuse and addiction } & Animated neuroscience video \\
\hline & Guest speaker on drug addiction \\
\hline \multirow[t]{2}{*}{ Day 7: Cancer therapies } & Lab: nicotine lab \\
\hline & Guest speaker on cancer \\
\hline \multirow[t]{3}{*}{ Day 8: Drugs for obesity } & Marketing project \\
\hline & Research: design research poster \\
\hline & Guest speaker on obesity \\
\hline \multirow[t]{2}{*}{ Day 9: Drugs for Parkinson's disease } & Movie: Awakenings \\
\hline & Guest speaker on Parkinson's disease \\
\hline \multirow[t]{3}{*}{ Day 10: Wrap-up } & Poster session \\
\hline & Pharmacojeopardy \\
\hline & Ice cream social \\
\hline
\end{tabular}

${ }^{\mathrm{a} P B L}=$ problem-based learning.

number of other opportunities for active learning. As displayed in Table 2, other activities included the use of two problem-based learning modules, which provided students with the opportunity to work in small groups to carry out online research related to drug absorption and elimination, respectively (a problem-based learning module on the cell biology of steroids has been included in the Supplemental Material). In another activity, students acted out the pharmacokinetic properties of four drugs, including the routes of administration, where and how the drug is metabolized, and how it is excreted. Concept maps, completed by students in small groups, were used as summary activities several times throughout the minicourse to encourage students to organize and synthesize the concepts learned throughout the day, which aligns with the constructivist approach to teaching

Table 3. Example of participants' hypothetical research proposals during the Summer minicourse ${ }^{a}$

Blueberries enhance memory by encouraging neurogenesis

Using resveratrol to model the treatment of noise-induced hearing loss in mice

The Use of Dabrafenib to Induce Apoptosis/Senescence in Hairy Cell Leukemia

Increased synaptic connections through the introduction of Pam protein

The use of cibacron blue to inhibit inflammation in mice

Vitamin D supplementation as a treatment for depression in rats

a'Titles represent students' original wording. and learning. Additional activities included movies directly related to pharmacology and four $\mathrm{PhD}$-level seminar speakers who talked about their current research.

Fall Research Course. Students who were randomly assigned to participate in the Fall research course were asked to provide the program faculty with three ideas for an investigation of the effects of a drug or toxin in the treatment of a disease or production of toxicity, respectively. Subsequently, we selected one research idea for each student that could be addressed using one of three types of experimental approaches available in our teaching lab: molecular, cellular, or behavioral (see Table 4 for examples of student research projects using these three approaches). We had already

Table 4. Examples of Fall research course participants' project titles, models, and approaches utilized

\begin{tabular}{|c|c|c|}
\hline Approach & Project title $^{\mathrm{a}}$ & Model \\
\hline Molecular & $\begin{array}{l}\text { Examining the effect of Vitamin } \mathrm{E} \\
\text { on genes associated with liver } \\
\text { cancer in zebrafish }\end{array}$ & $\begin{array}{l}\text { Tumor promoters } \\
\text { and polymerase } \\
\text { chain reaction }\end{array}$ \\
\hline Cellular & $\begin{array}{l}\text { The preventative effects of aloe } \\
\text { vera on neuromast oxidative } \\
\text { damage in zebrafish larvae }\end{array}$ & $\begin{array}{l}\text { Oxygen radical- } \\
\text { induced neuronal } \\
\text { damage }\end{array}$ \\
\hline Behavioral & $\begin{array}{l}\text { Effects of chronic caffeine use on } \\
\text { learning and memory in adult } \\
\text { zebrafish }\end{array}$ & $\begin{array}{l}\text { Learning and } \\
\text { memory }\end{array}$ \\
\hline
\end{tabular}

aTitles represent students' original wording. 
developed basic methodological procedures for each of these approaches using zebrafish (both larvae and adults) that students could use as a framework for answering their specific research questions. (These procedures were unrelated to the lab activities during the Summer minicourse.) In several cases, students went beyond the established approaches to develop a new methodology that was better suited to their proposed research project. All students used zebrafish as their model system, as zebrafish are a very useful animal model to test the effects of a drug on a biological response. The short life span and simple treatment paradigm allowed for the use of an animal model in a class-based research course, which would not have been possible with a more complex animal model (e.g., rodents).

During the semester, students with similar research questions were assigned to work in research pods of four to six students. Research pods met one night each week for $4 \mathrm{~h}$. In some cases, students came into the lab on another night to treat their fish or perform an additional experiment. Each student worked on his or her project independently, with guidance from an instructor. At times, students within a research pod also worked collaboratively to develop shared control trials or methodologies that could be used for their individual experiments.

During the first $2 \mathrm{wk}$ of the semester, students spent time learning basics about lab research and then consulted the literature concerning the background for their research idea. With guidance from their instructors, students finalized their research questions and hypotheses and then generated a shopping list of reagents they would need to perform their experiments. Instructors helped students learn the actual techniques and guided them to the literature for reviews about their techniques. At the end of the semester, students prepared final written reports and orally presented their research projects using a conference-style 10-min PowerPoint presentation. All students received both formative and summative feedback on their projects throughout the semester.

Design Principles. Both the Summer minicourse and Fall research course were designed to promote active learning and motivation. The majority of the day during the Summer program was devoted to active learning. As described previously, students engaged in open-guided inquiry in small groups through the four laboratory experiments, two problem-based learning modules, and other small-group activities (e.g., pharmacokinetics activity, concept maps). Active learning was also supported through students' development of their research proposals. While there were a few passive activities (e.g., lecture, guest speakers, movies), all of these activities included components designed to encourage some active learning. For instance, one guest speaker brought genetically modified "transparent" zebrafish that she used in her research, so students could see some of the unique properties of zebrafish. In lecture, the use of think-pair-share occurred frequently to encourage students to actively process the materials being presented. Additionally, the entire Fall research course was an active-learning experience.

Five motivational design principles were incorporated into both the Summer minicourse and the Fall research course. The first design principle, using real-world challenging tasks, was incorporated into the selection of pharmacology as the subject matter. As shown in Table 2, the Summer minicourse centered on real-world applications of basic principles in biology and chemistry, with a specific focus in the second week on the use of drugs to treat common diseases (e.g., obesity, cancer). The focus on pharmacology for the Fall research course also supported application to the real world, as students selected topics of critical importance to society or of personal relevance to investigate.

The second and third design principles, provision of choice (i.e., autonomy support) and encouragement of active involvement, were also key underlying themes in the instructional design of the Summer minicourse and Fall research course. The predominant use of active learning and open-guided inquiry supports students' autonomy, as students are key decision makers in how to proceed with the learning activities. Moreover, student choice was supported by allowing students to select their own research topics related to the research proposal (Summer minicourse) and Fall research. These same activities are, by their very nature, supportive of students' active involvement in learning.

We targeted our fourth design principle, support for feelings of belonging, in a variety of ways. During the Summer minicourse, we set up on-campus housing, so students were housed in adjacent rooms in a single residence hall. We also provided breakfast and lunch for students daily. These social structures afforded the opportunity for informal interactions among students throughout the 2-wk program. Additionally, there were a number of opportunities for small-group work. We varied whether students stayed with the same group (e.g., lab group, research proposal group) or switched groups (e.g., problem-based learning modules, pharmacokinetics activity, concept maps) to support sustained social interactions while also providing the opportunity to interact with a variety of students within the Summer program. During the Fall research course, students worked in small research pods, as described earlier. These pods were an important source of social support, as students often used similar experimental techniques, sometimes even sharing control groups, thus allowing them to problem solve as a team while still carrying out individual research. Finally, we made an effort to select instructors with good social skills, with whom we thought the students could relate. As part of the program, instructors interacted with students during free times (e.g., lunch, breakfast) and shared with the students their pathways into graduate school. In addition, we designated one lunch session during the Summer minicourse for instructors to talk with a group of four to five students about their career pathways.

Our final motivational design principle, use of effort-based evaluation, was focused on students' growth (learning) and understanding, rather than normative performance relative to their peers. To promote a focus on evaluation based on effort and learning, we did not grade the Summer minicourse. Students received informal evaluation about the quality of their work and their effort as they worked in small groups. Additionally, instructors evaluated students' research proposals, developed during the Summer minicourse, through the provision of written, ungraded, feedback throughout the development process. After the poster session in which the research proposals were presented, students received formative feedback on their posters, with a focus on the organization and visual/oral presentation of the poster and on their justification for the study, clarity of the hypotheses, and 
connection of hypotheses to the experimental design. Thus, the emphasis of this final formative evaluation of the research proposals was on the overall quality of their work.

In contrast to the Summer minicourse, students received a grade and full course credit for the Fall research course. However, the emphasis was on formative evaluation rather than normative performance. Students completed rough drafts and had the opportunity to revise and improve upon their final papers and proposals before submitting the final version for a grade. Again, the emphasis was on both improvement and the overall quality of students' responses. By providing students with a number of opportunities to revise and develop each portion of their written research project, student effort was emphasized more than normative performance. Moreover, a large portion of the grade was based on students' work during the semester (e.g., designing and carrying out their experiments) rather than on the summative products produced. We provided a grading rubric to the instructors for the research course, which emphasized students' effort (active participation in conducting their research projects, turning in assignments and responding to feedback, etc.), to maintain consistency and fairness in grading among all of the instructors.

Another motivational feature of the Summer miniprogram included a short-term psychological intervention designed to teach students that intelligence can develop and grow with effort (i.e., it is incremental). Students were randomly assigned to either an incremental ability (treatment; modeled after Aronson et al., 2002) or control condition. For the control condition, students watched a webinar developed by one of the authors providing basic neuroscience concepts and the neurobiology of drug abuse and addiction. Students in the incremental condition saw the same webinar, but there was additional information embedded within the webinar demonstrating that hard work can increase the size of brain areas associated with cognition, and hence intelligence. The next day, an exercise was used to reinforce and internalize the message that intelligence is malleable. Students in both the control and incremental conditions were asked to write a letter to an at-risk middle school student about what they learned in the webinar. Students in the incremental ability condition focused their letters on the message that it is possible to overcome challenges and succeed, especially with hard work, to reinforce the message they received during the webinar. Students in the control condition were asked to write about how drugs and alcohol impair brain function.

\section{Practical Considerations}

Several features of the program were important in the design and implementation. First, the costs totaled approximately $\$ 80,000$ per year (not including faculty effort). The major cost categories were stipends to the postdoc and graduate student instructors (up to $\$ 4000$ /instructor), the reagents for the lab research $(\$ 10,000-15,000)$, and costs associated with providing food and housing to participants during the Summer minicourse $(\sim 20,000)$. Additionally, the faculty members (co-principal investigators) involved with the development, implementation, and evaluation of the program received 15$25 \%$ effort for their role; however, it is difficult to separate out the effort specifically related to implementing the program from the other elements (design and evaluation). The majority of students paid for their own housing during the Summer program, although we did provide supplements or full reimbursement for housing for students with moderate to severe financial need.

\section{Evaluation}

Knowledge Assessment. Students completed a knowledge assessment (pretest) on the first day of the Summer minicourse. The assessment consisted of multiple-choice questions targeting concepts in biology (11 questions) and chemistry (nine questions). On the final day of the Summer minicourse, a posttest was administered that contained the same questions as the pretest but with the questions reordered. We did not provide students with answers to the pretest after they completed it. However, many concepts presented during the course included the correct answers to the pretest questions. Reliability analyses were not performed, because the individual questions assessing biology or chemistry targeted different concepts. Thus, we would not expect students' responses to all of the biology (or chemistry) questions to be highly correlated. Sample items for knowledge content assessment are as follows.

1. What is the function of the enzyme called a "kinase"?

a. It increases kinetics of cellular signaling reactions.

b. It cleaves chemokines.

c. It moves phosphate groups from one molecular to another.

d. It generates cyclical AMP.

e. don't know

2. An acid that does not dissociate completely in water is called:

a. a strong acid

b. a weak acid

c. ionized

d. hydrophobic

e. don't know

Students did not receive a grade for either assessment, nor were they told in advance that they would be asked to complete the assessments.

Motivational Beliefs and Program Assessment. To complement findings related to participants' gains in content knowledge, we also assessed the motivational effects of our pharmacology enrichment program (see Tables 5 and 6). All measures displayed adequate internal reliability (indicated by Cronbach's alpha; see Table 5) and model fit (indicated by confirmatory factor analyses) at both time points (after the Summer minicourse and at follow-up).

Participants provided self-reports on their science motivation directly following the Summer minicourse and during their fourth semester in college, approximately o1 mo after completing the Fall research assessment (i.e., follow-up assessment). Motivation was assessed using four well-established measures: interest (Conley, 2012), selfefficacy (Estrada et al., 2011), mastery-approach goal orientation (Midgley et al., 2000), and performance-approach goal orientation (Midgley et al., 2000). These complementary constructs assess different aspects of students' motivation toward science, including their interest in science (interest), confidence in their ability to perform research-related tasks 
Table 5. Self-report measures and sample items ${ }^{a}$

\begin{tabular}{|c|c|c|c|c|}
\hline Scale & $\begin{array}{l}\text { Number of } \\
\text { items }\end{array}$ & \multicolumn{2}{|c|}{ Reliability $(\alpha)$} & \multirow[t]{2}{*}{ Sample items } \\
\hline Science motivation & & $\begin{array}{l}\text { Post-Summer } \\
\text { minicourse }\end{array}$ & $\begin{array}{l}\text { Follow-up assessment } \\
\text { (sophomore year) }\end{array}$ & \\
\hline Interest & 4 & 0.89 & 0.90 & Science is exciting to me. \\
\hline Self-efficacy & 6 & 0.86 & 0.90 & $\begin{array}{l}\text { I am confident that I can use scientific literature } \\
\text { and/or reports to guide research. }\end{array}$ \\
\hline $\begin{array}{l}\text { Mastery-approach goal } \\
\text { orientation }\end{array}$ & 5 & 0.76 & 0.84 & $\begin{array}{l}\text { One of my goals in science is to learn as much as I } \\
\text { can. }\end{array}$ \\
\hline Incremental beliefs & 8 & 0.94 & 0.93 & $\begin{array}{l}\text { No matter who you are, you can significantly change } \\
\text { your intelligence level. }\end{array}$ \\
\hline \multicolumn{2}{|l|}{ Program perceptions } & $\begin{array}{l}\text { Summer } \\
\text { minicourse }\end{array}$ & Fall research course ${ }^{b}$ & \\
\hline Connection to real life & $4 / 3$ & 0.89 & 0.86 & $\begin{array}{l}\text { My [program] instructors relate course material to } \\
\text { real life. }\end{array}$ \\
\hline $\begin{array}{l}\text { Feelings of belonging in } \\
\text { program }\end{array}$ & 4 & 0.87 & 0.91 & [Felt] very welcome (1) to NOT very welcome (10) \\
\hline Instructor is personable & 11 & 0.95 & 0.96 & My [program] instructors are approachable. \\
\hline Perceived mastery goal structure & 7 & 0.83 & 0.87 & In [this program], trying hard is very important. \\
\hline $\begin{array}{l}\text { Perceived performance goal } \\
\text { structure }\end{array}$ & 5 & 0.90 & 0.85 & $\begin{array}{l}\text { In [this program], it's important to do better than } \\
\text { other students. }\end{array}$ \\
\hline \multicolumn{5}{|c|}{$\begin{array}{l}\text { aAll science motivation and program perception items measured on a five-point Likert-type scale except for "Feelings of belonging in } \\
\text { program," which was measured on a 10-point scale, and "Incremental beliefs," which was measured on a 6-point scale. The "Feelings of } \\
\text { belonging in program" scale was reverse-coded such that high ratings indicated higher levels of belonging. }\end{array}$} \\
\hline
\end{tabular}

in science (self-efficacy), focus on developing learning and understanding (mastery-approach goal), and focus on demonstrating competence, or looking smart, in comparison with others (performance-approach goal). Based on the five design principles outlined earlier, our pharmacology enrichment program was designed to increase the first three variables (interest, self-efficacy, mastery goals) but decrease performance-approach goals. Specifically, the focus on real-world challenging tasks that could be completed successfully with effort was designed to enhance interest, mastery goals, and self-efficacy. Autonomy support and active involvement were included to enhance interest and mastery goals, while support for belonging specifically targeted interest. Finally, the use of criterion-based evaluation was included to enhance mastery goals and self-efficacy and to decrease performance-approach goals. We also included a measure of theories of intelligence (Dweck, 1999), which assesses the degree to which individuals view intelligence as fixed or malleable (incremental). This measure served as a manipulation check for the incremental ability condition.

Participants also reported their perceptions of the Summer minicourse and Fall research course. Specifically, seven measures were selected to gauge the extent to which students perceived the Summer minicourse and Fall research course as motivationally supportive. Our first motivational design principle, the use of real-world challenging tasks, was assessed by asking students to report about the connections between the course materials and real life using a measure developed by Linnenbrink-Garcia et al. (2013). After the Summer minicourse and Fall research course, we measured our second design principle, perceived provision of choice, using a six-item adaptation of the Learning Climate Questionnaire (Black and Deci, 2000), which assesses autonomy support. Our third design principle, active involvement, was assessed using two slightly different three-item opportunities for involvement scales developed for this study. Our fourth design principle, feelings of belonging, was assessed with two different scales: one focused on students' overall perceptions of belonging during the Summer minicourse and Fall research course (Asher and Weeks, 2014), and the other assessed how personable students perceived the instructors to be (adapted from Linnenbrink-Garcia et al., 2013). Our fifth and final design principle placed an emphasis on effort-based evaluation and de-emphasized competition. To gauge students' perceptions of this design principle, we used two subscales from the Patterns of Adaptive Learning Scales (Midgley et al., 2000), assessing the extent to which participants perceived the program as focused on learning and development (mastery goal structure) or on competition (performance goal structure).

Institutional Records. Students who participated in the pharmacology enrichment program provided us with access to their institutional records. From these records, we identified students' majors and coded them as science related (e.g., biology, neuroscience, biomedical engineering) or non science. We also gathered information about whether 
Table 6. Participants' science motivation and program perceptions ${ }^{\mathrm{a}}$

\begin{tabular}{|c|c|c|}
\hline & Mean (SD) & $\begin{array}{c}\text { \% Students } \\
\text { agree/strongly } \\
\text { agree }\end{array}$ \\
\hline \multicolumn{3}{|c|}{ Science motivation post-Summer minicourse } \\
\hline Interest & $4.51(0.52)$ & 91.9 \\
\hline Self-efficacy & $3.94(0.61)$ & 54.3 \\
\hline Mastery-approach goals & $4.45(0.43)$ & 93.0 \\
\hline Performance-approach goals & $3.03(0.91)$ & 21.5 \\
\hline \multicolumn{3}{|c|}{ Science motivation at follow-up (Sophomore) } \\
\hline Interest & $4.34(0.62)$ & 87.9 \\
\hline Self-efficacy & $3.89(0.68)$ & 60.6 \\
\hline Mastery-approach goals & $4.27(0.56)$ & 83.4 \\
\hline Performance-approach goals & $2.89(0.92)$ & 23.8 \\
\hline \multicolumn{3}{|c|}{ Summer minicourse program assessment } \\
\hline Connection to real life & $4.08(0.73)$ & 72.1 \\
\hline Autonomy support & $3.98(0.69)$ & 58.6 \\
\hline Opportunities for involvement & $3.98(0.52)$ & 61.3 \\
\hline Feelings of belonging in program & $7.72(1.53)$ & 75.4 \\
\hline Instructor is personable & $4.15(0.64)$ & 65.1 \\
\hline Perceived mastery goal structure & $4.22(0.55)$ & 71.9 \\
\hline $\begin{array}{l}\text { Perceived performance goal } \\
\text { structure }\end{array}$ & $2.06(0.75)$ & 1.1 \\
\hline \multicolumn{3}{|l|}{ Fall research course assessment } \\
\hline Connection to real life & $4.01(0.64)$ & 69.3 \\
\hline Autonomy support & $4.25(0.53)$ & 74.4 \\
\hline Opportunities for involvement & $4.62(0.55)$ & 87.3 \\
\hline Feelings of belonging in program & $8.62(1.06)$ & 95.5 \\
\hline Instructor is personable & $4.46(0.54)$ & 84.8 \\
\hline Perceived mastery goal structure & $4.18(0.53)$ & 69.6 \\
\hline $\begin{array}{l}\text { Perceived performance goal } \\
\text { structure }\end{array}$ & $2.16(0.75)$ & 3.8 \\
\hline
\end{tabular}

${ }^{a}$ Values reflect ratings from students in cohorts 1-3 of the program. All constructs measured on a five-point scale; "Feelings of belonging in program" measured on a 10-point scale. Higher scores indicate greater levels of endorsement. "\% Students agree/strongly agree" represents students who responded with a 4 or 5 for all scales except for "Feelings of belonging in program" (represents students responding 7 or above). Fall research course assessment consists of responses from students in Fall research course only.

the students elected to concentrate in pharmacology, an option available for students majoring in biology or chemistry. Additionally, we drew from a larger set of deidentified institutional data available to determine the overall proportion of biology and chemistry majors at the same institution who concentrated in pharmacology, subtracting out the number of pharmacology enrichment program participants so we could compare these two groups. To capture final selections on majors and pharmacology concentrations, we report data from students who had recently graduated or were in their senior year (first two cohorts of program participants) as an indication of their persistence in science.

\section{RESULTS}

\section{Content Knowledge}

To determine the effect of participating in the Summer enrichment program, we assessed students' knowledge of basic biology and chemistry concepts before and after the Summer minicourse for students in all $4 \mathrm{yr}$ of our program. Posttest scores were compared with pretest scores to assess the shortterm impact of the Summer program on competence in basic principles of biology and chemistry (Figure 1). It is important to note that students had some limited background knowledge in these fields, having taken high school biology and chemistry. Additionally, all but a few students in our sample took a chemistry course in the first year of college, but many waited until their sophomore year to take the biology core courses. A repeated-measures analysis of variance, with time as a within-subjects factor, indicated that there were statistically significant gains in both biology $(F(1,219)=154.94, p<0.0001)$ and chemistry $(F(1,219)=38.01, p<0.0001)$ knowledge. After the Summer minicourse, participants demonstrated an average knowledge gain of $15 \%$ in biology and $8 \%$ in chemistry, suggesting that the Summer minicourse was effective in enhancing students' knowledge in both biology and chemistry.

\section{Science Motivation and Program Perceptions}

Next, we examined participants' science motivation and students' perceptions of the program as motivationally supportive after completing the Summer minicourse and Fall research course. These analyses were conducted for participants in cohorts 1-3 of the program, as data for the follow-up assessment (i.e., 8 mo after the Summer program) had not yet been collected from cohort 4 participants.

Beliefs about Intelligence. We first conducted a manipulation check to determine whether the incremental ability condition enhanced students' beliefs that intelligence is malleable (e.g., incremental, or it can develop and grow), relative to those in the control group. Incremental ability beliefs significantly differed as a function of incremental ability condition both after the Summer minicourse $(F(1,181)=$ 33.37, $p<0.001)$ and at the follow-up assessment $(F(1,166)=$ $7.65, p=0.006)$. As expected, participants in the incremental ability condition reported higher incremental beliefs (Summer minicourse: $\mathrm{M}=4.75, \mathrm{SD}=0.79$; follow-up assessment: $\mathrm{M}=4.39, \mathrm{SD}=0.87$ ) compared with students in the control condition (Summer minicourse: $\mathrm{M}=3.94, \mathrm{SD}=1.06$; follow-up assessment: $\mathrm{M}=3.99, \mathrm{SD}=1.07)$.

Science Motivation. To determine whether differences in the within-program conditions (incremental ability, Fall research experience) should be considered or whether we

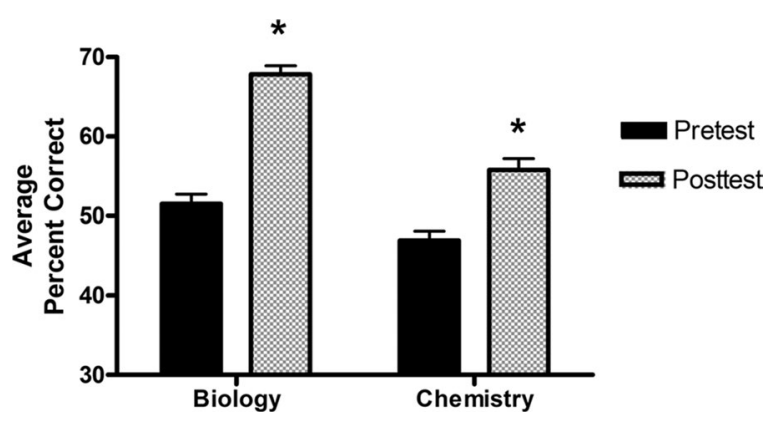

Figure 1. Gains in biology and chemistry content knowledge ( \pm SEM) over the course of the Summer minicourse. Pretest was assessed on the first day of the Summer minicourse; posttest was assessed on the last day of the Summer minicourse. Repeated-measures ANOVAs indicated that pretest and posttest differed significantly for biology and chemistry, ${ }^{*}, p<0.0001$. 
Table 7. MANOVA to test for within-program effects

\begin{tabular}{|c|c|c|c|}
\hline & Pillai's T & $d f$ & $p$ value \\
\hline \multicolumn{4}{|c|}{ Science motivation post-Summer minicourse } \\
\hline Incremental versus control & 1.93 & 4,181 & 0.11 \\
\hline \multicolumn{4}{|l|}{$\begin{array}{l}\text { Science motivation at follow-up } \\
\text { (sophomore) }\end{array}$} \\
\hline Incremental versus control & 0.89 & 4,163 & 0.47 \\
\hline Fall research course versus none & 0.64 & 4,163 & 0.63 \\
\hline $\begin{array}{l}\text { Incremental condition } \times \text { fall } \\
\text { research experience condition }\end{array}$ & 0.85 & 4,163 & 0.50 \\
\hline \multicolumn{4}{|c|}{ Summer minicourse program assessment } \\
\hline Incremental versus control & 0.97 & 10,139 & 0.47 \\
\hline
\end{tabular}

could collapse across (i.e., combine) conditions for our analyses of student motivation, we tested whether there were significant differences in students' science motivation as a function of the two within-program conditions using two multivariate analyses of variance (MANOVAs). We found no significant differences among the groups as a function of these conditions (see Table 7). Therefore, in our subsequent primary analyses, we collapsed across the two conditions.

Table 6 provides a summary of participants' average ratings of their science motivation and the percentage of students whose average ratings indicated that they agreed or strongly agreed with the items. Immediately following the Summer minicourse and continuing into their sophomore year (i.e., follow-up), on average, program participants reported high levels of interest, self-efficacy, and mastery-approach goals in science. These three forms of motivation were specifically targeted through our motivational design principles and are considered to be beneficial for students' engagement and learning. The findings are particularly pronounced for interest and mastery-approach goals, with $83-93 \%$ of participants indicating they agree or strongly agree with the items. Notably, students also reported very low levels of performance-approach goals (e.g., trying to look smart or outperform others), with only around 20-25\% of participants agreeing or strongly agreeing with these items. As our pharmacology enrichment program was designed to de-emphasize performance goals, this pattern of findings is aligned with the goals of the program. Taken together, the pattern of results suggests that students participating in any component of our pharmacology enrichment program displayed high levels of adaptive science motivation both after the Summer minicourse and Fall research course components.

Program Perceptions. Table 6 also displays participants' perceptions of a number of key motivational design principles incorporated within the Summer minicourse and the Fall research course. The measures assessing the Summer minicourse perceptions were completed by all students; measures assessing the Fall research course were only completed by students who participated in the Fall research course. Parallel to the analyses for science motivation, we first examined whether there were differences in Summer program perceptions for students in the incremental ability versus control conditions using a one-way (incremental, control) MANOVA. Participants in these two conditions did not significantly differ (see Table 7); thus, we collapsed across the incremental ability condition for the Summer program perception analyses. As the Fall program perceptions were only completed by students who participated in the Fall research experience, we did not test for any differences between conditions for these analyses.

Overall, students' ratings indicate that they perceived both the Summer minicourse and the Fall research course to be motivationally supportive. Across both experiences, students rated connections to real life, autonomy support, opportunities for involvement, feelings of belonging, and mastery goal structure very highly (see Table 6); means ranged from 3.98 to 4.62 (5-point scale) with between 58.6 and $84.8 \%$ of the students agreeing or strongly agreeing with the items in these scales. Moreover, given that the pharmacology enrichment program was specifically designed to de-emphasize performance goals, or a focus on demonstrating competence, it is very encouraging that fewer than $4 \%$ of students in the Fall research course and 1\% in the Summer minicourse reported the course as emphasizing performance goals. Together, these results suggest that participants perceived both the Summer minicourse and Fall research course as motivationally supportive based on our five design principles, which is in keeping with the overall reported high levels of science motivation previously reported.

\section{Selection of Majors}

Finally, we examined students' selection of major and decision to concentrate in pharmacology. For these analyses, we focused on students in cohorts 1 and 2. Students in these two cohorts recently graduated or were in their senior year, which allowed us to have more accurate data as students often shift majors and typically do not declare concentrations until later in their college careers.

As expected, a majority ( $83 \%$ ) of the pharmacology program participants majored in science (e.g., a biological, chemical, or biomedical field). Because we introduced pharmacology as a subject area to students participating in the program, we were especially interested in whether their participation may have impacted their decision to focus on pharmacology as a subdiscipline. At our university, students who major in biology and chemistry have the option to concentrate in a variety of subdisciplines within the biological and chemical sciences, (e.g., pharmacology, biochemistry, genetics). Of those who participated in the pharmacology-based enrichment program (i.e., those who participated in the minicourse, regardless of their participation in the Fall research course), 53 of the 127 participants majored in biology or chemistry. From this group who had the option of focusing on pharmacology, $26 \%$ chose to concentrate in pharmacology. In contrast, only $7 \%$ of all biology and chemistry majors $(n=378)$ during the same two academic years as our participants chose to concentrate in pharmacology. A chi-square test for independence indicated that biology and chemistry students who participated in the pharmacology enrichment program were more likely to concentrate in pharmacology than students who did not participate in the pharmacology enrichment program $(X 2(1)=19.09, p<0.001)$.

We were also interested in determining whether students who participated in both the Summer minicourse and the Fall research course would be more likely to concentrate in 
Table 8. Percentage of program participants and nonparticipants concentrating in pharmacology ${ }^{a}$

\begin{tabular}{lccc}
\hline & $\begin{array}{c}\text { Summer } \\
\text { minicourse } \\
\text { only }\end{array}$ & $\begin{array}{c}\text { Summer } \\
\text { minicourse }+ \\
\text { Fall research } \\
\text { course }\end{array}$ & $\begin{array}{c}\text { Non } \\
\text { program } \\
\text { participants }\end{array}$ \\
\hline $\begin{array}{c}\text { \% Biology/chemistry } \\
\text { majors concentrating } \\
\text { in pharmacology }\end{array}$ & 18.50 & 34.60 & 7.40 \\
$\begin{array}{c}\text { Total number of biology/ } \\
\text { chemistry majors }\end{array}$ & 27 & 26 & 378 \\
\hline
\end{tabular}

aNumbers represent participants from the first two program years.

pharmacology than students who participated in the Summer minicourse alone. Results from an ancillary chi-square analysis indicated that students who participated in the Summer minicourse only, students who participated in the Summer minicourse plus the Fall research course, and nonparticipants differed in their likelihood to concentrate in pharmacology $(X 2(2)=23.00, p<0.001)$. As displayed in Table 8, program participants in both the Summer minicourse only and Fall research course conditions concentrated in pharmacology more often than students who did not participate in our program. Fall research course participants in particular were likely to concentrate in pharmacology, with more than one-third of biology and chemistry majors concentrating in pharmacology. These ancillary analyses, however, should be interpreted with caution; chi-square tests require that expected sample sizes for each cell be greater than five, an assumption that was violated in this ancillary analysis. A future analysis after the next cohort can be assessed may address this cautious interpretation.

\section{DISCUSSION}

Currently, there is a shortage of individuals educated in the United States who are pursuing science careers, leading to a future talent deficit in STEM-related fields (Hawley et al., 2014). One contributing factor to this shortage is that, while many individuals enter college with the intention of pursuing a science-related career, a significant proportion drop the STEM major for a variety of reasons (PCAST, 2012; Chen, 2013). In an attempt to address this shortage, we developed a pharmacology enrichment program designed to increase students' biology and chemistry knowledge, science motivation, and, ultimately, increase the number of students studying pharmacology. In this paper, we provide a rich description of our pharmacology enrichment program, detailing how we utilized active learning and five motivational design principles that are based in educational and psychological theory and research to create a Summer minicourse and Fall research course. Overall, our evaluation of the program suggests that it was beneficial in terms of supporting 1) increases in students' biology and chemistry content knowledge, 2) high levels of adaptive science motivation, and 3) decisions to major in biology or chemistry and to concentrate in pharmacology. Below, we highlight several key lessons learned and consider implications for practice and future research.

A key strength of our approach was the integration of research teams trained in both the basic sciences (pharmacology) and educational psychology. With this background, we were able to develop an engaging Summer minicourse and Fall research course that not only supported students' learning but also their science motivation and subsequent persistence in science throughout college. Thus, an important lesson learned from our approach is the need for multidisciplinary teams consisting of content experts and experts on student learning and engagement when designing educational enrichment programs. Building from this expertise, we identified several key elements of our pharmacology enrichment program.

First, the inclusion of active learning was critical for supporting students' learning and motivation. Instead of providing traditional lectures, we implemented various active-learning methods (e.g., think-pair-share) during the lecture period to engage the students. In addition, problem-based learning activities were used to reinforce concepts learned during the lecture. Active learning is often discussed in the context of precollege education; however, some studies illustrate that active learning is also useful in undergraduate and graduate pharmacology-based courses. For instance, active learning in pharmacology-related topics has resulted in improvement in student understanding when used with nursing students (Kaylor, 2014), medical students (Zgheib et al., 2010), and PharmD (doctor of pharmacy) students (Satyanarayanajois, 2010). Among undergraduates enrolled in STEM courses, a recent meta-analysis comparing active learning with traditional lecturing also provides evidence of the benefits of active learning (Freeman et al., 2014). Thus, our results highlighting the gains in student knowledge and motivation as a result of participating in our pharmacology Summer minicourse are in keeping with prior research in which educators use active learning in the context of pharmacology instruction and among undergraduate populations in STEM.

Second, the use of five motivational design principles appeared effective in terms of students' overall levels of motivation, perceptions of the Summer program, and decisions to major in biology or chemistry and to concentrate in pharmacology. The use of these motivational design principles in relation to a pharmacology enrichment program is particularly novel. While many STEM enrichment programs seek to enhance psychological variables such as interest or self-efficacy (e.g., Bakken et al., 2010), very few work directly with motivational researchers to embed research-based design elements that target multiple forms of motivation simultaneously. For our program, we drew from decades of empirical research and motivational theory (e.g., Turner et al., 2011; Linnenbrink-Garcia et al., 2013) to identify and implement five motivational design principles: 1) inclusion of real-world challenging tasks, 2) provision of choice surrounding academic tasks, 3) encouragement of active involvement, 4) support for feelings of belonging, and 5) use of effort-based evaluation) to support science self-efficacy, science interest, and a focus on learning and understanding (i.e., mastery goal). We describe how these principles were embedded in both the Summer minicourse and Fall research course and then provide evidence, based on students' perceptions of both 
components of our program, that our efforts to implement the designed principles were effective. We encourage others interested in addressing the leaky pipeline in STEM fields to take a similar approach. These five motivational design principles can be readily applied to a variety of fields of study and programs.

Notably, we also included a short-term psychological intervention (e.g., Yeager and Walton, 2011) designed to encourage program participants to endorse the belief that intelligence is malleable rather than fixed. Although the benefits of incremental ability beliefs is well documented (Yeager and Dweck, 2012), we found no added benefit for students randomly assigned to the incremental ability condition in terms of students' science motivation either immediately after the Summer minicourse or 8 mo later (after the Fall research course). Future analyses over the next several years will determine whether there is a long-term benefit of the incremental ability exercise on science motivation.

Another important design element in our pharmacology enrichment program was the inclusion of an early independent research experience (e.g., Fall research course). We chose to implement the early research experience as a "best practice" in undergraduate science education. Authentic research experiences for undergraduates have been shown to improve science interest and student engagement (Seymour et al., 2004; Frantz et al., 2006; Lopatto, 2007; Harrison et al., 2011; Eagan et al., 2013). Additionally, retrospective research suggests that early research experiences often lead to an increase in interest in science careers and pursuit of a $\mathrm{PhD}$ (Russell et al., 2007). Most research experiences occur later in the undergraduate career (during students' third and fourth years); however, the report from PCAST (2012) recommends engaging students in research courses and research programs in the first $2 \mathrm{yr}$ of college. Early research experiences are expected to increase students' positive attitudes toward science and decrease attrition in STEM fields (Nagda et al., 1998; Russell et al., 2007; Carter et al., 2009). Authentic research experiences for undergraduate students typically consist of participation in an ongoing project in a laboratory of their choice. In our pharmacology enrichment program, the authentic research experience was actually self-generated from individual interest and carried out in our teaching lab, not in the lab of a specific faculty member. Our ancillary analyses examining the percentage of students concentrating in pharmacology provide some evidence for the effectiveness of these types of self-generated research experiences for supporting students' persistence in science, particularly in pharmacology. Surprisingly, however, students who participated in the Fall research course in addition to the Summer minicourse did not significantly differ from those who did the Summer minicourse alone in terms of their science motivation. However, future analyses will inform us whether the Fall research course can significantly enhance the effects of the Summer enrichment experience on science persistence over longer time periods.

In closing, we provide proof of concept that it is possible to develop and implement a pharmacology-based enrichment program building from current research in both education and psychology. Moreover, our results provide initial support for the benefits of taking this approach. We found statistically significant increases in biology and chemistry knowledge and a significantly greater proportion of students participating in our enrichment program concentrated in pharmacology several years later. We also documented overall high levels of adaptive forms of science motivation (self-efficacy, interest, mastery goals) and provided evidence that students did indeed perceive the pharmacology enrichment program as aligned with our motivational design principles. Given these encouraging findings, we urge educators to consider incorporating into their classrooms/labs active learning and the five motivational design principles presented here that support students' learning and science motivation.

\section{ACKNOWLEDGMENTS}

This work was supported by NIH R01 GM094534-04.

\section{REFERENCES}

Aronson J, Fried CB, Good C (2002). Reducing the effects of stereotype threat on African American college students by shaping theories of intelligence. J Exp Soc Psychol 38, 113-125.

Asher SR, Weeks MS (2014). Loneliness and belongingness in the college years. In: The Handbook of Solitude: Psychological Perspectives on Social Isolation, Social Withdrawal, and Being Alone, ed. RJ Coplan and JC Bowker, Hoboken, NJ: Wiley-Blackwell.

Bakken LL, Byars-Winston A, Gundermann DM, Ward EC, Slattery A, King A, Scott D, Taylor RE (2010). Effects of an educational intervention on female biomedical scientists' research self-efficacy. Adv Health Sci Educ 15, 167-183.

Black AE, Deci EL (2000). The effects of instructors' autonomy support and students' autonomous motivation on learning organic chemistry: a self-determination theory perspective. Sci Educ 84, 740-756.

Carter FD, Mandell M, Maton KI (2009). The influence of on-campus, academic year undergraduate research on STEM Ph.D. outcomes: evidence from the Meyerhoff Scholarship Program. Educ Eval Policy Anal 31, 441-462.

Chen X (2013). STEM Attrition: College Students' Paths Into and Out of STEM Fields, Washington, DC: National Center for Education Statistics, Institute of Education Sciences, U.S. Department of Education.

Conley AM (2012). Patterns of motivation beliefs: combining achievement goal and expectancy-value perspectives. J Educ Psychol 104, 32-47.

Dickman A, Morris D, Postlethwait J, Udovic D, Wetherwax P (2002). Workshop biology: demonstrating the effectiveness of active learning in an introductory biology course. Bioscience 52, 272-281.

Dweck CS (1999). Self-Theories: Their Role in Motivation, Personality, and Development, Philadelphia: Taylor and Francis/Psychology Press.

Eagan MK Jr, Hurtado S, Chang MJ, Garcia GA, Herrera FA, Garibay JC (2013). Making a difference in science education: the impact of undergraduate research programs. Am Educ Res J 50, 683-713.

Ebert-May D, Brewer C, Allred S (1997). Innovation in large lectures-teaching for active learning. Bioscience 47, 601-607.

Estrada M, Woodcock A, Hernandez PR, Schultz PW (2011). Toward a model of social influence that explains minority student integration into the scientific community. J Educ Psychol 103, 206-222.

Frantz KJ, DeHaan RL, Demetrikopoulos MK, Carruth LL (2006). Routes to research for novice undergraduate neuroscientists. Cell Biol Educ 5, 175-187. 
Freeman S, Eddy SL, McDonough M, Smith MK, Okoroafor N, Jordt $\mathrm{H}$, Wenderoth MP (2014). Active learning increases student performance in science, engineering, and mathematics. Proc Natl Acad Sci USA 111, 8410-8415.

Graham MJ, Frederick J, Byars-Winston A, Hunter A-B, Handelsman J (2013). Increasing persistence of college students in STEM. Science $341,1455-1456$.

Haak DC, HilleRisLambers J, Pitre E, Freeman S (2011). Increased structure and active learning reduce the achievement gap in introductory biology. Science 332, 1213-1216.

Handelsman J, Ebert-May D, Beichner R, Bruns P, Chang A, DeHaan R, Gentile J, Lauffer S, Stewart J, Tilghman SM, Wood WB (2004). Scientific teaching. Science 304, 521-522.

Harrison M, Dunbar D, Ratmansky L, Boyd K, Lopatto D (2011). Classroom-based science research at the introductory level: changes in career choices and attitude. CBE Life Sci Educ 10, 279-286.

Hawley CE, McMahon BT, Cardoso ED, Fogg NP, Harrington PE, Barbir LA (2014). College graduation to employment in STEM careers: the experience of new graduates at the intersection of underrepresented racial/ethnic minority status and disability. Rehabil Res Policy Educ 28, 183-199.

Hmelo-Silver CE, Duncan RG, Chinn CA (2007). Scaffolding and achievement in problem-based and inquiry learning: a response to Kirschner, Sweller, and Clark (2006). Educ Psychol 42, 99-107.

Jensen JL, Lawson A (2011). Effects of collaborative group composition and inquiry instruction on reasoning gains and achievement in undergraduate biology. CBE Life Sci Educ 10, 64-73.

Kaylor SK (2014). Preventing information overload: cognitive load theory as an instructional framework for teaching pharmacology. J Nurs Educ 53, 108-111.

Linnenbrink-Garcia L, Patall EA, Messersmith EE (2013). Antecedents and consequences of situational interest. Br J Educ Psychol 83, 591-614.

Lopatto D (2007). Undergraduate research experiences support science career decisions and active learning. CBE Life Sci Educ 6, 297-306.
McGee R, Keller JL (2007). Identifying future scientists: predicting persistence into research training. CBE Life Sci Educ 6, 316-331.

Midgley C, Maehr ML, Hruda LZ, Anderman E, Anderman L, Freeman KE, Gheen M, Kaplan A, Kumar R, Middleton MJ, et al. (2000). Manual for the Patterns of Adaptive Learning Scales (PALS), Ann Arbor: University of Michigan.

Nagda BA, Gregerman SR, Jonides J, von Hippel W, Lerner JS (1998). Undergraduate student-faculty research partnerships affect student retention. Rev High Ed 22, 55-72.

Palincsar AS (1998). Social constructivist perspectives on teaching and learning. Annu Rev Psychol 49, 345-375.

President's Council of Advisors on Science and Technology (2012). Engage to Excel: Producing One Million Additional College Graduates with Degrees in Science, Technology, Engineering, and Mathematics, Washington, DC: U.S. Government Office of Science and Technology.

Russell SH, Hancock MP, McCullough J (2007). The pipelinebenefits of undergraduate research experiences. Science 316, 548549.

Satyanarayanajois SD (2010). Active-learning exercises to teach drug-receptor interactions in a medicinal chemistry course. Am J Pharm Educ 74, 147.

Seymour E, Hunter AB, Laursen SL, Deantoni T (2004). Establishing the benefits of research experiences for undergraduates in the sciences: first findings from a three-year study. Sci Educ 88, 493-534.

Turner JC, Warzon KB, Christensen A (2011). Motivating mathematics learning: changes in teachers' practices and beliefs during a ninemonth collaboration. Am Educ Res J 48, 718-762.

Yeager DS, Dweck CS (2012). Mindsets that promote resilience: when students believe that personal characteristics can be developed. Educ Psychol 47, 302-314.

Yeager DS, Walton GM (2011). Social-psychological interventions in education: they're not magic. Rev Educ Res 81, 267-301.

Zgheib NK, Simaan JA, Sabra R (2010). Using team-based learning to teach pharmacology to second year medical students improves student performance. Med Teach 32, 130-135. 